\title{
Rash and loss of vision in a 60-year-old woman with systemic lupus erythematosus
}

\author{
Monica C. Sandu MD, Soumya Chatterjee MD MS
}

See also practice article by White and colleagues at www.cmaj.ca/lookup/doi/10.1503/cmaj.101213

1 60-year-old woman was admitted to hospital for evaluation of sudden onset of visual loss in both eyes. The day before admission, sudden blurring of vision had developed, with the appearance of black floaters almost simultaneously in both eyes. This was followed by rapid deterioration of vision over the course of the next four to six hours, leading to perception of bright light only. There was no preceding history of trauma, pain or redness in the eyes, headache or fever. She had noticed a rash on her arms and legs for the past two weeks but had not sought medical attention.

The patient had a 10-year history of systemic lupus erythematosus, which would relapse occasionally. During relapses, her symptoms mostly consisted of fatigue, intermittent low-grade fever, polyarthralgia, myalgia, serositis (pleurisy and pleural effusion), and a waxing and waning maculopapular rash on her extremities. She had no history of renal or neurologic involvement. Previous laboratory evaluation showed positive results for antinuclear antibody, double-stranded DNA antibody, lymphopenia and hypocomplementemia, but negative results for anticardiolipin antibodies. At the time of presentation, the patient was taking hydroxychloroquine $100 \mathrm{mg}$ twice daily, prednisone $15 \mathrm{mg}$ daily and azathioprine $75 \mathrm{mg}$ daily.

On examination, the patient looked unwell and quite anxious. She was afebrile, her heart rate was 85 beats/min and her blood pressure was $150 / 83 \mathrm{~mm} \mathrm{Hg}$. Her pupils were equal, round and sluggishly responsive to light; there was no afferent pupillary defect. Extraocular movements were intact. Her visual acuity was reduced bilaterally to perception of hand motion only. There were palpable purpuric rashes on her upper and lower extremities, with oozing and crusting associated with ulceration of some of these lesions around the ankles (Figure 1A and B). The rest of her examination was unremarkable.

The patient was admitted to hospital and underwent urgent ophthalmology consultation. On slit-lamp examination, the anterior segment was normal bilaterally with white conjunctiva, clear cornea, deep and quiet anterior chamber and flat iris. The findings on retinal examination, which included macular edema, swelling of the optic discs, extensive hemorrhage, tortuous veins, and sheathing of the retinal vessels, are shown in Figure $1 \mathrm{C}$ and D. Most of the relevant laboratory results returned within 24-48 hours and are summarized in Table 1. Tests for liver, renal and thyroid function, electrolytes and muscle enzymes were normal. Computed tomography of the brain was also negative.

\section{What is your diagnosis?}
a. Hypertensive retinopathy
b. Retinal vasculitis
c. Cytomegalovirus retinitis
d. Antiphospholipid syndrome
e. Paraproteinemia

The most likely diagnosis is retinal vasculitis leading to central retinal vein occlusion and central retinal artery occlusion. Retinal examination (Figure 1C and D) showed findings consistent with bilateral extensive central retinal vein occlusion (tortuous veins, extensive hemorrhages and optic disc swelling) and central retinal artery occlusion (macular edema with acute and profound loss of vision bilaterally). There was sheathing of the retinal vessels, which is characteristic of vasculitis. There were a few inflammatory cells in the anterior chamber and in the vitreous.

In the setting of systemic lupus erythematosus in a patient with bilateral visual loss, lymphope-
Competing interests: None declared.

This article has been peer reviewed.

Correspondence to: Dr. Soumya Chatterjee, chattes@ccf.org

CMAJ 2012. DOI:10.1503 /cmaj.101941 
nia, negative anticardiolipin antibodies, and elevated erythrocyte sedimentation rate and C-reactive protein level, the ophthalmoscopic findings supported the diagnosis of active retinal vasculitis. Other conditions that should be considered based on the appearance on fundoscopic examination include diabetic retinopathy, malignant hypertension, cytomegalovirus retinitis, antiphospholipid syndrome, and hyperviscosity syndrome associated with paraproteinemias. Our patient did not have diabetes. Although she had a history of hypertension, it was generally under control, and her blood pressure on admission was not particularly high. She did not have a paraprotein. Results were negative for anticardiolipin antibodies, $\beta$-2 glycoprotein-1 antibodies and lupus anticoagulant. Hence, based on her clinical profile (no history of miscarriages or prior history of thrombosis) and negative laboratory results, antiphospholipid syndrome was ruled out. Patients receiving immunosuppressive medications are at risk for cytomegalovirus retinitis. However, the ophthalmoscopic findings in our patient were not characteristic of this condition, which typically presents with a white granular zone of retinal necrosis that progresses in a centrifugal, "brush fire" pattern, associated with variable degrees of hemorrhage. Moreover, blood culture and polymerase chain reaction tests for cytomegalovirus were later found to be negative (Table 2).

\section{What immediate treatment should be recommended?}

a. Intravenous cyclophosphamide

b. Plasmapheresis

c. Intravenous pulse methylprednisolone

d. Anticoagulation

e. Antiplatelet therapy (acetylsalicylic acid or clopidogrel)

The best answer is intravenous pulse methylprednisolone. In lupus retinopathy, careful ophthalmologic evaluation is essential in establishing the correct diagnosis and in guiding therapy. When vision is affected by retinal vasculitis (as in this patient), systemic corticosteroids are the mainstay of therapy, with or without other immunosuppressive agents. ${ }^{1,2}$ However, in the absence of ocular symptoms, presence of retinal changes does not necessarily require specific therapy, but warrants periodic ophthalmologic evaluation and surveillance. ${ }^{2,3}$

During the acute phase, it may be clinically challenging to distinguish between a vasculitic and a thrombotic retinal event, particularly
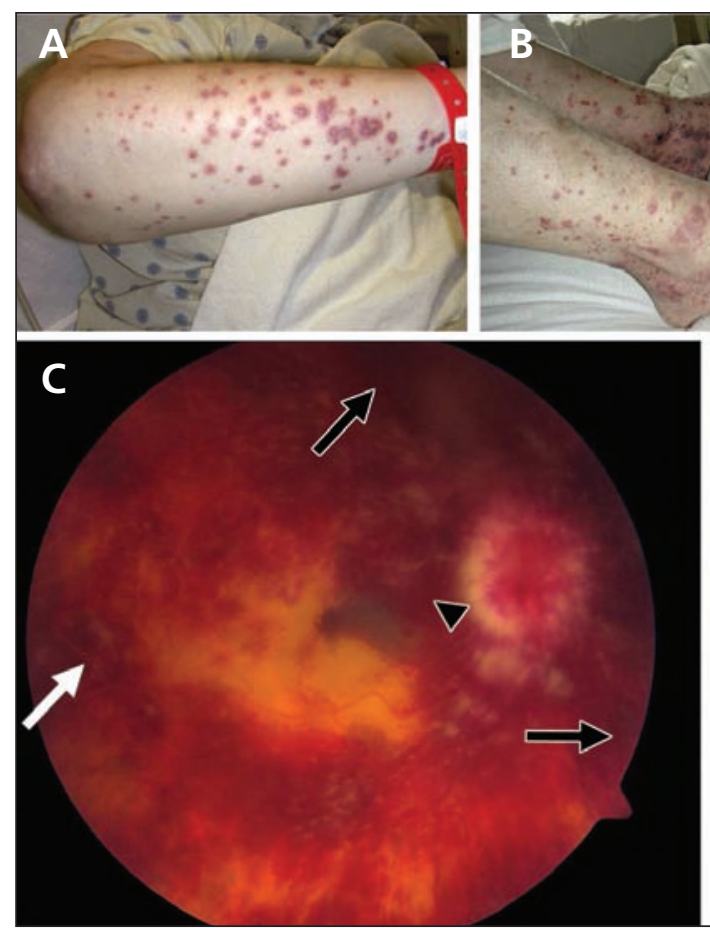
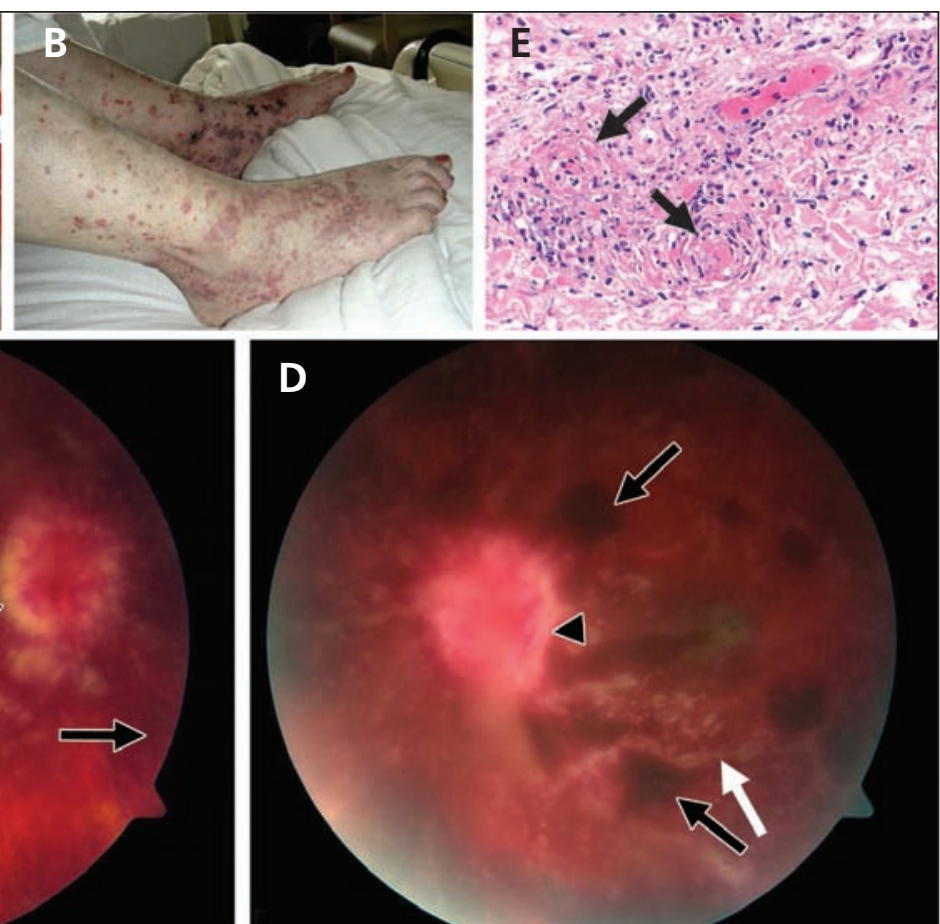

Figure 1: (A, B) Palpable purpuric rashes on the upper and lower extremities of a 60-year-old woman with sudden onset of visual loss. Retinal images of the right (C) and left (D) eyes showing extensive hemorrhages (black arrows), tortuous veins, sheathing of the retinal vessels (white arrows) and swelling of the optic discs (arrowheads). (E) Photomicrograph of biopsy specimen showing a perivascular neutrophilic infiltrate (arrows) and other features consistent with a leukocytoclastic vasculitis (hematoxylin-eosin, original magnification $\times 40$ ). 
because antiphospholipid syndrome may first manifest as vaso-occlusive retinal disease. Diagnosis of the latter would lead to consideration of anticoagulation or antiplatelet agents for secondary prevention of thrombosis. All decisions regarding treatment should be made in close collaboration with an ophthalmologist.

In our patient, the clinical picture and the ophthalmoscopic findings were quite typical of severe retinal vasculitis. The ophthalmologist recommended aggressive immunosuppressive therapy, in an attempt to decrease activity of systemic lupus erythematosus, reduce intraocular inflammation, prevent permanent visual loss and avert complications in other vascular territories. Hence, treatment was started within 24 hours of admission, before some of the relevant laboratory results were available (Table 2). The regimen included daily intravenous pulse methylprednisolone and plasma exchanges for three days, followed by daily oral cyclophosphamide and prednisone. The results of testing for C3 and C4 levels, double-stranded DNA antibody titers, hepatitis B and C serology, and cytomegalovirus DNA by polymerase chain reaction were available two days after admission (Table 2). Final results of negative blood cultures were available in four days, and the results of cryoglobulins (low-positive levels) were available nine days after admission.

A biopsy had been taken of the rash from the patient's lower extremity, and that report was available in three days. It showed a perivascular neutrophilic infiltrate, vasculitis extending from the papillary dermis to the midreticular dermis, fibrin thrombi filling the lumen of many vessels, edema of the papillary dermis, and necrosis of the overlying epidermis with focal subepidermal vesicles (Figure 1E). Antibody localization using direct immunofluorescence showed immunoreactivity for immunoglobulin $\mathrm{M}$ within the vessels of the papillary and reticular dermis. Sections immunostained for immunoglobulins $\mathrm{G}$ and $\mathrm{A}$, and complement $\mathrm{C} 3 \mathrm{c}$ were negative. These findings were consistent with leukocytoclastic vasculitis.

Although the patient's rash improved with aggressive immunosuppressive therapy, there was no improvement in her vision during her hospital stay. She was discharged home with oral hydroxychloroquine, prednisone, cyclophosphamide, and dapsone for prophylaxis against pneumocystis. Further follow-up three months after discharge showed that her rash had largely resolved, but there was no improvement of her vision. Cyclophosphamide was continued for six months and thereafter switched to methotrexate because substantial neutropenia developed.
Table 1: Summary of laboratory results at presentation of a 60 -year-old woman with sudden onset of visual loss

\begin{tabular}{|c|c|c|}
\hline Investigation & Reference range & Result \\
\hline Leukocyte count, $\times 10^{9} / \mathrm{L}$ & $4.0-11.0$ & 5.39 \\
\hline Hemoglobin, g/L & $120-160$ & 99 \\
\hline Mean corpuscular volume, $\mathrm{fL}$ & $80-100$ & 83.1 \\
\hline Platelet count, $\times 10^{9} / \mathrm{L}$ & $150-400$ & 262 \\
\hline $\begin{array}{l}\text { Absolute neutrophil count, } \times 10^{9} / \mathrm{L} \\
\text { (neutrophil \%) }\end{array}$ & $\begin{array}{c}1.8-7.7 \\
(40 \%-70 \%)\end{array}$ & $4.44(82.3 \%)$ \\
\hline $\begin{array}{l}\text { Absolute lymphocyte count, } \\
\times 10^{9} / \text { L (lymphocyte } \% \text { ) }\end{array}$ & $\begin{array}{c}1.0-4.0 \\
(22 \%-44 \%)\end{array}$ & $0.44(8.2 \%)$ \\
\hline Total protein, g/L & $60-84$ & 74 \\
\hline Albumin, $\mathrm{g} / \mathrm{L}$ & $35-50$ & 32 \\
\hline Prothrombin time, $s$ & $9-13$ & 11.4 \\
\hline $\begin{array}{l}\text { Activated plasma thromboplastin } \\
\text { time, } s\end{array}$ & $23.0-32.4$ & 29.8 \\
\hline Urinalysis (protein) & Negative & Trace \\
\hline Gamma globulin, g/dL & $0.60-1.35$ & 1.67 \\
\hline $\begin{array}{l}\text { Antinuclear antibody (enzyme } \\
\text { immunoassay), OD ratio }\end{array}$ & $<1.5$ & 20.4 \\
\hline $\begin{array}{l}\text { Antinuclear antibody } \\
\text { (immunofluorescence assay) }\end{array}$ & Negative & $\begin{array}{c}>1: 640 \\
\text { (homogeneous) }\end{array}$ \\
\hline $\begin{array}{l}\text { Extractable nuclear antigens } \\
\text { panel }\end{array}$ & Negative & $\begin{array}{l}\text { Positive for SS-A } \\
\text { antibodies }\end{array}$ \\
\hline $\begin{array}{l}\text { Anticardiolipin antibodies (IgG, } \\
\lg M, \lg A)\end{array}$ & $<9$ & $<9$ \\
\hline Lupus anticoagulant & Negative & Negative \\
\hline $\begin{array}{l}\text { Erythrocyte sedimentation rate, } \\
\mathrm{mm} / \mathrm{h}\end{array}$ & $0-30$ & 122 \\
\hline C-reactive protein, $\mathrm{mg} / \mathrm{L}$ & $0-20$ & 79 \\
\hline
\end{tabular}

Table 2: Additional test results that were available after the diagnosis was made and treatment was started

\begin{tabular}{|lcc|}
\hline Investigation & Reference range & Result \\
\hline $\begin{array}{l}\text { Double-stranded DNA antibody, } \\
\text { IU/mL }\end{array}$ & $<30$ & 37 \\
\hline $\begin{array}{l}\text { Double-stranded DNA antibody } \\
\text { using Crithidia luciliae as substrate }\end{array}$ & Negative & Positive \\
\hline C3, g/L & $0.68-2.60$ & 1.11 \\
\hline $\begin{array}{l}\text { C4, g/L } \\
\text { Cryoglobulin quantitative, } \mathrm{mg} / \mathrm{mL}\end{array}$ & $0.12-0.46$ & 0.08 \\
\hline $\begin{array}{l}\text { Cytomegalovirus DNA by } \\
\text { polymerase chain reaction } \\
\text { (blood) }\end{array}$ & $0-50$ & 64 \\
\hline Blood cultures & Negative & Negative \\
\hline Hepatitis B and C serology & Negative & No growth \\
\hline Skin biopsy & Negative & Negative \\
\hline
\end{tabular}




\section{Discussion}

The prevalence of retinal involvement in systemic lupus erythematosus is variable and depends on the severity of the underlying disease. It ranges from $3 \%$ in patients with stable disease to $29 \%$ in patients with active systemic lupus erythematosus. ${ }^{1}$ Classic retinopathy in systemic lupus erythematosus, characterized by cotton-wool spots, frequently affects both eyes. It results from retinal vasculitis associated with immune complex deposition. ${ }^{4}$ Cotton-wool spots appear as puffy yellowish-white patches, resulting from focal impairment of retinal blood supply, leading to injury and swelling of the superficial nerve fibre layer of the retina. Antiphospholipid antibody syndrome, on the other hand, may be associated with severe vasoocclusive retinopathy, often with unilateral, but sometimes bilateral, involvement of the eyes. ${ }^{5}$

In a series of 52 patients with systemic lupus erythematosus, cotton-wool spots were found to correlate with lupus activity, but not with central nervous system lupus. ${ }^{6}$ Vision is preserved in most common forms of lupus retinopathy, even with extensive cotton-wool spots. ${ }^{4,6}$ However, lupus retinopathy is more commonly observed in patients with more active and systemic disease and hence tends to correlate with decreased survival. ${ }^{4}$
Our patient's presentation illustrates a particularly dramatic onset of bilateral blindness, from retinal vasculitis causing central retinal vein occlusion and central retinal artery occlusion. When this complication affects both eyes, the visual prognosis is poor. ${ }^{3}$ Vision-threatening vasoocclusive retinal disease causing widespread ischemia, disc vasculitis leading to damage of the optic nerve, and involvement of the larger retinal vessels are rare, but catastrophic, complications of active systemic lupus erythematosus. ${ }^{1.6}$

Diagnosis of retinal vasculitis is purely clinical and is made by ophthalmoscopic examination, which shows characteristic vascular sheathing (visible accumulation of inflammatory cells along vessel walls). Minimal anterior chamber cells as well as vitritis (as in our patient) are common. ${ }^{2}$ Retinal vascular abnormalities may be demonstrated by fluorescein angiography, which shows perivascular leakage indicating an increase in vascular permeability. However, fluorescein angiography is of little value in the setting of widespread retinal hemorrhages (as in our patient) and may need to be performed two to three months after the acute episode to look for neovascularization and vitreous hemorrhages. Additionally, fluorescein angiography has often been found to be unhelpful in the evaluation of patients with lupus retinal vasculitis. ${ }^{6}$

Table 3 summarizes the therapeutic options in

Table 3: Therapeutic options in retinopathy and retinal vasculitis in systemic lupus erythematosus*

\begin{tabular}{|c|c|}
\hline \multirow[t]{4}{*}{ Corticosteroids ${ }^{1,2}$} & Considered as initial therapy for most patients \\
\hline & $\begin{array}{l}\text { Periocular corticosteroid injections can be used in mild to moderate } \\
\text { unilateral disease }\end{array}$ \\
\hline & $\begin{array}{l}\text { Systemic corticosteroids are reserved for moderate to severe ocular } \\
\text { involvement: oral prednisone } 1-2 \mathrm{mg} / \mathrm{kg} \text { per day, with or without initial } \\
\text { pulse therapy of intravenous methylprednisolone ( } 1 \mathrm{~g} \text { per day for 3-6 } \\
\text { days) }\end{array}$ \\
\hline & $\begin{array}{l}\text { Many patients will show clinical improvement only 3-4 weeks after } \\
\text { starting treatment, regardless of treatment schedule used }\end{array}$ \\
\hline \multirow[t]{2}{*}{$\begin{array}{l}\text { Other immunosuppressive } \\
\text { medications }^{1,2,7}\end{array}$} & $\begin{array}{l}\text { Cyclophosphamide, mycophenolate mofetil, azathioprine, chlorambucil, } \\
\text { cyclosporine, tacrolimus and methotrexate have been used as steroid- } \\
\text { sparing agents or for patients with substantial retinal disease who do } \\
\text { not respond to systemic steroid therapy alone }\end{array}$ \\
\hline & $\begin{array}{l}\text { In severe vaso-occlusive disease, which may be a manifestation of } \\
\text { antiphospholipid syndrome, immunosuppressive treatment is not useful }\end{array}$ \\
\hline Plasmapheresis ${ }^{1,7}$ & $\begin{array}{l}\text { May be tried in severe retinal vasculitis, usually combined with } \\
\text { immunosuppressive therapy (cyclophosphamide or methotrexate) }\end{array}$ \\
\hline $\begin{array}{l}\text { Aspirin and/or } \\
\text { anticoagulation therapy }\end{array}$ & $\begin{array}{l}\text { Used with variable degrees of success in patients with severe vaso- } \\
\text { occlusive retinopathy associated with antiphospholipid syndrome }\end{array}$ \\
\hline $\begin{array}{l}\text { Rituximab (anti-CD20 } \\
\text { monoclonal antibody) }\end{array}$ & $\begin{array}{l}\text { Single case report of successful use for retinal vasculitis in a patient } \\
\text { with systemic lupus erythematosus with improvement in vision }\end{array}$ \\
\hline \multirow{2}{*}{$\begin{array}{l}\text { Pan-retinal laser } \\
\text { photocoagulation and } \\
\text { vitreoretinal surgical } \\
\text { procedures }^{1,2}\end{array}$} & $\begin{array}{l}\text { These procedures are used to treat complications associated with } \\
\text { retinal vasculitis (neovascularization, vitreous hemorrhage and } \\
\text { neovascular glaucoma) to limit further loss of vision }\end{array}$ \\
\hline & $\begin{array}{l}\text { Immunosuppressive therapy should be used to achieve control of } \\
\text { intraocular inflammation before start of laser treatment }\end{array}$ \\
\hline
\end{tabular}


retinopathy and retinal vasculitis in systemic lupus erythematosus. Unfortunately, optimal treatment of retinopathy and retinal vasculitis associated with systemic lupus erythematosus is not well defined owing to a lack of well-designed clinical trials. ${ }^{2}$ Apart from corticosteroids, other immunosuppressive medications are used either as steroid-sparing agents or for patients who do not respond to systemic steroids alone (Table 3). Papadaki and colleagues described two instances of retinal vasculitis in systemic lupus erythematosus that were treated with plasmapheresis along with immunosuppressive treatment (intravenous cyclophosphamide in one patient and oral methotrexate in the other), with substantial improvement of vision. ${ }^{7}$ Rituximab, a monoclonal antibody to B-lymphocyte antigen CD20, has also been reported to be effective in an instance of severe lupus retinal vasculitis. ${ }^{8}$

\section{The case revisited}

Six months after the onset of blindness, the patient started to experience vivid visual hallucinations. She had no auditory hallucinations or cognitive impairment and had good insight into her disease. This condition is known as Charles Bonnet syndrome and involves visual hallucinations in a visually impaired person, in the absence of psychiatric illness. ${ }^{9}$ She was referred to a low vision clinic for further counselling.

Our patient recently died from an unrelated illness. Up until her death, her vision had remained severely impaired, with perception of light only, and in the last three years of her life, she continued to experience vivid and quite distressing complex visual hallucinations.

\section{References}

1. Davies JB, Rao PK. Ocular manifestations of systemic lupus erythematosus. Curr Opin Ophthalmol 2008;19:512-8.

2. Walton RC, Ashmore ED. Retinal vasculitis. Curr Opin Ophthalmol 2003;14:413-9.

3. Tomasini DN, Segu B. Systemic considerations in bilateral central retinal vein occlusion. Optometry 2007;78:402-8.

4. Stafford-Brady FJ, Urowitz MB, Gladman DD, et al. Lupus retinopathy. Patterns, associations, and prognosis. Arthritis Rheum 1988;31:1105-10

5. Montehermoso A, Cervera R, Font J, et al. Association of antiphospholipid antibodies with retinal vascular disease in systemic lupus erythematosus. Semin Arthritis Rheum 1999;28:326-32.

6. Lanham JG, Barrie T, Kohner EM, et al. SLE retinopathy: evaluation by fluorescein angiography. Ann Rheum Dis 1982;41:473-8.

7. Papadaki TG, Zacharopoulos IP, Papaliodis G, et al. Plasmapheresis for lupus retinal vasculitis. Arch Ophthalmol 2006;124:1654-6.

8. Hickman RA, Denniston AK, Yee CS, et al. Bilateral retinal vasculitis in a patient with systemic lupus erythematosus and its remission with rituximab therapy. Lupus 2010;19:327-9.

9. Rovner BW. The Charles Bonnet syndrome: a review of recent research. Curr Opin Ophthalmol 2006;17:275-7.
Affiliations: From the Division of Immunology (Rheumatology) (Sandu), Department of Internal Medicine, University of Iowa Hospitals and Clinics, Iowa City, Iowa; and the Cleveland Clinic Lerner College of Medicine of Case Western Reserve University, and the Department of Rheumatic and Immunologic Diseases (Chatterjee), Cleveland Clinic, Cleveland, Ohio

Contributors: Both authors were involved in drafting the article or revising it critically for important intellectual content, and both authors approved the final version submitted for publication.

CMAJ remains committed to notifying readers in a timely way about advisories and warnings pertaining to serious adverse drug events. A collection of recent drug advisories from Health Canada and the US Food and Drug Administration is regularly updated at www.cmaj.ca/misc/advisories.xhtml. 